\title{
KEMAMPUAN MENENTUKAN UNSUR INTRINSIK PUISI KARYA SOETARDJI CALZOUM BACHRI
}

\author{
Syamsuriani ${ }^{1}$, Suhartini Khalik ${ }^{2}$, dan Suleha Ecca ${ }^{3}$, H. Agussalim ${ }^{4}$ \\ ${ }^{1,2,3}$ Universitas Muhammadiyah Sidenreng Rappang \\ Jalan Angkatan 45 No. 1A Lautang Salo Rappang \\ syamdani@gmail.com
}

\begin{abstract}
Abstrak: Kemampuan Menentukan Unsur Intrinsik Puisi Karya Soetardji Calzoum Bachri. Penelitian ini bertujuan memperoleh data tentang kemampuan menentukan unsur intrinsik dalam puisi karya Sutardji Calzoum Bachri. Populasi penelitian ini adalah seluruh siswa kelas X SMA Negeri 6 Pinrang yang berjumlah 128 siswa, sampel penelitian ini ditarik dengan cara cluster sampling yakni 31 siswa. Teknik yang digunakan dalam pengumpulan data adalah teknik dekomentasi dan tes. Data dianalisis dengan menggunakan teknik statistik deskriptif dalam bentuk persentase. Berdasarkan hasil analisis data diketahui bahwa siswa sebanyak 27 siswa $(87,10 \%)$ tuntas belajarnya. Sehingga disimpulkan bahwa siswa mampu menentukan unsur puisi Tragedi Shika dan Winka karya Sutardji Calzoum Bachri siswa kelas X SMA Negeri 6 Pinrang Kabupaten Pinrang. Dengan demikian, disarankan agar guru Bahasa Indonesia terus memtovasi siswa untuk meningkatkan kemampuannya dalam mengapresiasi karya sastra.
\end{abstract}

Kata kunci: karya sastra, puisi, unsur intrinsik.

\begin{abstract}
Ability to Determine Intrinsic Elements of Poetry by Soetardji Calzoum Bachri. This study aims to obtain data on the ability to determine the intrinsic elements in poetry by Sutardji Calzoum Bachri. The population of this study were all students of class $\mathrm{X}$ SMA Negeri 6 Pinrang totaling 128 students, the sample of this study was drawn by cluster sampling, namely 31 students. The techniques used in data collection are decomentation and test techniques. Data were analyzed using descriptive statistical techniques in the form of percentages. Based on the results of data analysis, it is known that as many as 27 students $(87.10 \%)$ have completed their studies. So it was concluded that students were able to determine the elements of the poetry Tragedy of Shika and Winka by Sutardji Calzoum Bachri of class X SMA Negeri 6 Pinrang, Pinrang Regency. Thus, it is recommended that Indonesian language teachers continue to motivate students to improve their ability to appreciate literary works.
\end{abstract}

Keyword: literary works, poetry, intrinsic elements.

Salah satu karya sastra yang berkembang sangat pesat yaitu puisi. Bahkan sebelum Indonesia merdeka, masyarakat Indonesia sebenarnya telah bersastra yaitu dengan mantra, doa-doa untuk dewa atau nenek moyang. Hasil dari karya sastra baik yang berupa puisi, prosa, maupun drama telah diajarkan melalui bangku sekolah pada pengajaran bahasa Indonesia yang tidak hanya bertujuan agar siswa memiliki pengetahuan dan pengalaman, tetapi juga kemampuan untuk mengapresiasi dari hasil karya sastra tersebut.

Dalam pembelajaran sastra khususnya puisi siswa diharapkan mampu menentukan unsur intrinsik puisi yang berkaitan dengan standar kompetensi yang ada di sekolah terutama dalam keterampilan berbahasa yaitu membaca. Puisi merupakan salah satu wujud media komunikasi khusus melalui bahasa. 
Oleh karenanya puisi dapat dipahami atau dinikmati oleh pembaca melalui unsur-unsur yang terdapat di dalamnya. Puisi adalah karya sastra dengan bahasa yang dipadatkan, dipersingkat, dan diberi irama dengan bunyi yang padu dan pemilihan kata-kata (imajinatif). Kata-kata betul-betul terpilih agar memiliki kekuatan pengucapan. Walaupun singkat atau padat, namun berkekuatan (Waluyo, 2005; Djuanda et al., 2006).

Untuk mengapresiasi puisi biasanya dikaitkan dengan kegiatan seni. Apresiasi puisi berkaitan dengan kegiatan yang ada hubungannya dengan puisi, yaitu mendengar membaca mendalam (dengan penuh penghayatan, merasakan apa yang ditulis penyair, mampu menyerap nilai-nilai yang terkandung dalam puisi dan menghargai puisi sebagai karya seni dengan keindahan atau kelemahannya (Waluyo, 2005).

Munculnya bermacam-macam paham tersebut, menyebabkan kurang jelasnya dasar teori dan pendekatan dalam pelaksanaan kegiatan kemampuan makna puisi. Hal ini semakin mendukung adanya anggapan bahwa puisi sulit dipahami karena puisi memiliki bahasa yang berbeda dengan karya sastra lain, puisi dipandang sebagai mata pelajaran yang tidak menarik sehingga siswa tidak berusaha memahami puisi dengan sungguh-sungguh, sehingga proses pembelajaran puisi di sekolah kurang memuaskan.

Pemilihan unsur intrisik puisi sebagai subjek dalam penelitian didasarkan pada alasan, yakni 1) siswa pada umumnya kurang berminat memperdalam kesusastraan, khususnya puisi; 2) dipilihnya puisi karya Sutardji Calzoum Bachri, karena sudah diajarkan di sekolah dan karya-karyanya cukup dikenal siswa.

Penelitian serupa dilakukan oleh Nurcaya di tahun 2013 dengan judul "Kemampuan Menentukan Unsur-Unsur Intrinsik Puisi 'Sepi Saupi' Karya Sutardji Calzoum Bachri Siswa Kelas VIII MTs Negeri Baranti Kecamatan Baranti Kabupaten Sidenreng Rappang (Nurcaya, 2013). Sariana di tahun 2014 dengan judul "Kemampuan Memahami Unsur Intrinsik Puisi 'Doa' Karya Chairil Anwar Siswa kelas VII SMP Negeri 2 Baranti Kabupaten Sidenreng Rappang"
(Sariana, 2014). Penulis tertarik untuk mengadakan penelitian dengan judul yang serupa yaitu Kemampuan Menentukan Unsur Intrinsik Puisi Karya Sutardji Calzoum Bachri Siswa Kelas X SMA Negeri 6 Pinrang Kabupaten Pinrang. Namun, dengan puisi yang berbeda "Tragedi Shika dan Winka" dengan aspek penilaian yang berbeda.

Penelitian ini dimaksudkan agar siswa mampu menentukan unsur intrinsik puisi "Tragedi Shika dan Winka" karya Sutardji Calzoum Bachri dengan empat aspek penilaian yaitu tema, rasa (feeling), nada (tone), dan amanat dengan berpedoman pada teori Waluyo sedangkan peneliti terdahulu menilai dengan empat aspek yaitu tema gaya bahasa diksi dan amanat.

\section{METODE}

Desain yang digunakan dalam penelitian ini adalah desain deskriptif kuantitatif, karena pada dasarnya dalam penelitian ini mengukur kemampuan siswa dalam menentukan unsur-unsur intrinsik puisi Tragedi Shika dan Winka karya Sutardji Calzoum Bachri siswa kelas X SMA Negeri 6 Pinrang Kabupaten Pinrang.

Populasi penelitian ini berjumlah 128 siswa yang tersebar ke dalam empat kelas, yaitu X1, X2, X3, dan X4. Sampel dipilih dengan cara cluster sampling. Teknik ini memberikan peluang yang sama kepada setiap populasi untuk dipilih sebagai sampel (Sugiyono, 2017). Sehingga semua populasi diacak secara kelompok. Siswa kelas X4 terpilih sebagai sampel dengan jumlah 31 orang terdiri 19 perempuan dan 12 laki-laki. Data dikumpulkan melalui teknik dokumentasi dan tes. Dokumentasi digunakan untuk mengetahui banyaknya sampel penelitian. Tes digunakan untuk mengukur kemampuan siswa dalam menentukan unsur intrinsik puisi. Data dianalisis dengan menggunakan teknik statistic deskriptif dalam bentuk persentase dengan rumus berikut.

$\mathrm{P}=\frac{f}{\mathrm{~N}} \times 100 \%$

Keterangan:

$\mathrm{P}=$ persentase

$\mathrm{f}=$ frekuensi yang sedang dicari persentasenya 
$\mathrm{N}=$ banyaknya individu

(Sudijono, 2015)

\section{HASIL DAN PEMBAHASAN}

\section{Hasil Penelitian}

Data yang disajikan berikut ini adalah hasil tes yang menggambarkan pengaruh penggunaan metode inkuiri terhadap kemampuan membaca pemahaman cerita rakyat siswa.

Tabel 1 Klasifikasi, Distribusi Frekuensi dan Persentase Nilai

\begin{tabular}{cccc}
\hline No & $\begin{array}{c}\text { Klasifikasi } \\
\text { Nilai }\end{array}$ & Frekuensi & $\begin{array}{c}\text { Persentase } \\
(\mathbf{\%})\end{array}$ \\
\hline 1 & $91-100$ & 0 & $0 \%$ \\
\hline 2 & $81-90$ & 5 & $16,13 \%$ \\
\hline 3 & $71-80$ & 22 & $70,97 \%$ \\
\hline 4 & $61-70$ & 0 & $0 \%$ \\
\hline 5 & $\leq 60$ & 4 & $12,90 \%$ \\
\hline & Jumlah & $\mathbf{3 1}$ & $\mathbf{1 0 0 \%}$ \\
\hline
\end{tabular}

Sumber: hasil tes

Berdasarkan tabel 1 diketahui bahwa nilai siswa terbanyak pada rentang 71-80, yakni sebanyak 22 siswa $(70,97 \%)$.

Tabel 2 Nilai, Frekuensi, dan Persentase Ketuntasan Belajar

\begin{tabular}{ccccc}
\hline No & Nilai & Kategori & $\begin{array}{c}\text { Frekue } \\
\text { nsi }\end{array}$ & $\begin{array}{c}\text { Persentas } \\
\text { e }\end{array}$ \\
\hline 1 & $\geq 75$ & Tuntas & 27 & $87,10 \%$ \\
\hline 2 & $<75$ & $\begin{array}{c}\text { Belum } \\
\text { tuntas }\end{array}$ & 4 & $12,90 \%$ \\
\hline \multicolumn{3}{c}{ Jumlah } & 31 & $100 \%$ \\
\hline
\end{tabular}

Berdasarkan tabel 2 diketahui bahwa siswa yang tuntas sebanyak 27 siswa $(87,10 \%)$ dan siswa yang belum tuntas sebanyak 4 siswa $(12,90 \%)$.

\section{Pembahasan}

Pembahasan penelitian ini mencakup kemampuan siswa menentukan unsur intrinsik puisi "Tragedi Shika dan Winka". dengan berpedoman pada teori Waluyo yang mengemukakan bahwa unsur batin atau unsur intrinsik puisi merupakan wacana teks puisi secara utuh yang mengandung arti atau makna yang hanya dapat dilihat atau dirasakan melalui penghayatan yang terdiri dari tema, rasa (feeling), nada (tone), dan amanat .
Sebagai acuan dalam penelitian dapat dikemukakan bahwa kemampuan menentukan unsur-unsur intrinsik puisi merupakan memahami isi puisi. Kegiatan diawali dengan mengkaji gaya maupun bentuk sebagai suatu keutuhan isi puisi. Perhatian dipusatkan pada judul serta kekerapan kata. Kata-kata yang menjadi tanda dalam memahami tema. Bait yang berisi sedikit lirik menjadi tema puisi. Seperti halnya pada judul yang juga dapat membayangkan tema. Tetapi, judul belum tentu sama dengan tema. Mengetahui tema serta lirik merupakan langkah pertama yang harus dilakukan dalam upaya memahami puisi.

Hasil analisis data menunjukkan bahwa persentase siswa tuntas sebesar $87,10 \%$. Hal ini telah memenuhi syarat ketuntasan belajar siswa, yakni siswa dianggap tuntas belajar jika rata-rata nilai hasil belajar siswa lebih dari 60 dengan persentase ketuntasan klasikal lebih dari 85\% (Mulyasa, 2006). Oleh karena itu, dapat disimpulkan bahwa siswa kelas X SMA Negeri 6 Pinrang Kabupaten Pinrang mampu menentukan unsur intrinsik puisi Tragedi Shika dan Winka karya Sutardji Calzoum Bachri. Penelitian serupa juga menyimpulkan bahwa siswa mampu menentukan unsur intrinsik puisi sesuai dengan tuntutan kurikulum (Nurcaya, 2013; Sariana, 2014).

\section{PENUTUP}

Berdasarkan hasil analisis data diketahui bahwa sebanyak 27 siswa $(87,10 \%)$ tuntas belajarnya. Sehingga disimpulkan bahwa siswa mampu menentukan unsur puisi Tragedi Shika dan Winka karya Sutardji Calzoum Bachri siswa kelas X SMA Negeri 6 Pinrang Kabupaten Pinrang. Dengan demikian, disarankan agar guru Bahasa Indonesia terus memtovasi siswa untuk meningkatkan kemampuannya dalam mengapresiasi karya sastra. 


\section{DAFTAR PUSTAKA}

Djuanda, Dadan, \& Iswara. (2006). Apresiasi Sastra Indonesia. UPI Press.

Mulyasa, E. (2006). Kurikulum yang Disempurnakan. PT Remaja Rosdakarya.

Nurcaya. (2013). Kemampuan Menentukan Unsur-unsur Intrinsik Puisi Puisi "Sepisaupi" karya Sutardji Calzoum Bachri Siswa kelasVIII Mts Negeri Baranti Kecamatan Baranti Kabupaten Sidenreng Rappang. STKIP Muhammadiyah Rappang.

Sariana. (2014). Kemampuan Memahami Unsur Intrinsik Puisi 'Doa' Karya Chairil Anwar Siswa kelas VII SMP Negeri 2 Baranti Kabupaten Sidenreng Rappang. STKIP Muhammadiyah Rappang.
Sudijono, A. (2015). Pengantar Statistik Pendidikan. PT. Raja Grafindo Persada. Sugiyono. (2017). Metode Penelitian Kuantitatif, Kualitatif, dan $R \& D$. Alfabeta.

Waluyo, J. H. (2005). Teori dan Apresiasi Puisi. Erlangga. 